ARTIGOS 


\title{
Freire e Vygotsky: um diálogo com pesquisas e sua contribuição na Educação em Ciências
}

\author{
Simoni Tormöhlen Gehlen *, Otavio Aloisio Maldaner ** e Demétrio Delizoicov ***
}

Resumo: O presente estudo constitui-se numa revisão de trabalhos que tomam como objeto de pesquisa as interlocuçôes entre o pensamento de Freire e Vygotsky na educação escolar, com o objetivo de explicitar os principais elementos explorados nessas articulaçóes. Metodologicamente, a pesquisa compreende uma revisão em atas de eventos da área de Educação e Educação em Ciências e, mediante o emprego da Análise Textual Discursiva, examina as seguintes articulaçôes entre as ideias de Freire e Vygotsky: linguagem, concepção de conhecimento e mediação. Sinaliza-se que os estudos identificados não dão a devida atenção à problematização, categoria fundamental em Freire, assim como pouco exploram a significação conceitual baseada em Vygotsky. Essas categorias podem contribuir no envolvimento e no nível de aprendizagem dos estudantes da Educação Básica, para as mudanças necessárias no Ensino de Ciências.

Palavras-chave: Freire e Vygotsky; ensino de Ciências; problematização; significação conceitual.

\section{Freire and Vygotsky: a dialogue with pieces of research and contributions to science education}

Abstract: This study is a review of works focusing on interlocutions between Freire's and Vygotsky's thinking on school education. It aims at eliciting and clarifying the main elements explored in such connections. In methodological terms, this research is a review of records of education and science education events. Through discoursive textual analysis, we have studied language, knowledge conception and mediation as connections between Freire's and Vygotsky's ideas. We have observed that the identified studies do not provide the needed attention to problematization, an essential category for Freire, and they barely explore the conceptual signification based on Vygotsky. Considering the necessary changes in science teaching, these categories may contribute to elementary students' involvement and learning level.

Key words: Freire and Vygotsky; science education; problematization; conceptual signification.

\footnotetext{
* Departamento de Ciências Exatas e Tecnológicas da Universidade Estadual de Santa Cruz (UESC), Ilhéus, Bahia, Brasil. simonigehlen@yahoo.com.br

** Universidade Regional do Noroeste do Estado do Rio Grande do Sul (Unijuí), ljuí, RS, Brasil. maldaner@unijui.edu.br

**** Centro de Educação e Programa de Pós-Graduação em Educação Científica e Tecnológica da Universidade Federal de Santa Catarina (UFSC), Florianópolis, SC, Brasil. demetrio@ced.ufsc.br
} 
Introdução

Os pressupostos de Freire e Vygotsky, cada vez mais, têm auxiliado a configurar novas perspectivas teóricas no cenário da educação brasileira. No ensino de Ciências, os trabalhos que se referenciam em Vygotsky apresentam, por exemplo, discussões acerca do papel da linguagem no processo de ensino-aprendizagem, como Mortimer e Scott (2002), Mortimer (2000); da motivação relacionada aos processos interativos desencadeados em sala de aula (Monteiro et al., 2007; Monteiro; Gaspar, 2007); da inclusão de tópicos de Física moderna e contemporânea no Ensino Médio (Pereira; Ostermann; Cavalcanti, 2009; Ostermann et al., 2009), bem como configuraçōes curriculares, como os estudos de Maldaner (2007) e Maldaner e Zanon (2001). Os estudos que utilizam as ideias de Freire têm discutido aspectos como a reconfiguração curricular, como Torres et al. (2008), Delizoicov (1991, 2008), Silva (2004), Pontuschka (1993), Delizoicov, Angotti e Pernambuco (2002) e Pernambuco et al. (1988).

Apesar de as ideias de Freire e Vygotsky balizarem os estudos no âmbito do ensino de Ciências, Rodríguez-Arocho (2000) aponta que a literatura brasileira e estrangeira tem explorado os pressupostos desses autores quase sempre de forma isolada. Para a autora, existe uma predominância de referências particulares a Freire e Vygotsky, bem como a incipiência de estudos que mencionam os autores conjuntamente ou que, de alguma forma, vinculam suas ideias. Apesar disso, no Brasil, há estudos na área de Educação que centralizam suas discussões para a possível articulação entre o pensamento de Freire e Vygotsky, a exemplo de Marques e Marques (2006), Alves (2008) e Moura (2001, 2004), e, no âmbito da Educação em Ciências, Gehlen et al. (2008).

Embora esses estudos se empenhem na interlocução do pensamento de Freire e Vygotsky, pouco é conhecido sobre as principais questões que fomentam a articulação entre a abordagem vygotskyana e freireana. $\mathrm{O}$ objetivo deste estudo consiste em explicitar as interlocuções entre o pensamento de Freire e Vygotsky, realizadas por estudos nacionais e internacionais, envolvendo a área de Educação e Educação em Ciências, bem como sinalizar contribuições para a pesquisa em Educação em Ciências. Para tal, realizou-se uma revisão de trabalhos que tomam como objeto de estudo as articulaçóes entre o pensamento de Freire e Vygotsky, orientadas pelas seguintes questôes: Quais os principais elementos explorados nas articulações entre as ideias de Freire e Vygotsky? Quais as possíveis contribuições das articulações entre Freire e Vygotsky apresentadas pelas pesquisas na Educação em Ciências?

Nosso pressuposto é que alguns aspectos presentes nas articulações entre as ideias de Freire e Vygotsky compõem um construto teórico promissor para a 
pesquisa em Educação em Ciências, em especial, quanto à organização curricular.

\section{Procedimentos metodológicos}

A localização de estudos, num primeiro momento, deu-se por meio de incursão na internet, seguida do contato direto com seus autores, que viabilizaram o acesso a outros trabalhos relacionados ao assunto. A presença de discussões acerca das ideias de Freire e Vygotsky no material disponibilizado pelos autores impulsionou a extensão das investigações nas atas de quatro eventos realizados no Brasil relativos à Educação e Educação em Ciências, publicados entre o período de 1997 e 2008, e um evento internacional realizado em Porto Rico, em 2001.

Os seguintes eventos foram analisados: da $23^{\mathrm{a}}$ até a $31^{\mathrm{a}}$ Reunião Anual da Associação Nacional de Pós-Graduação e Pesquisa em Educação (ANPED), envolvendo o período de 2000 a 2008; I Conferência Internacional: o enfoque Histórico-Cultural em Questão, realizada em 2006; do I ao VI Encontro Nacional de Pesquisa em Educação em Ciências (ENPEC), de 1997 a 2007, e do I ao IV Colóquio Internacional Paulo Freire, no período de 2005 a 2007. Além desses eventos, também foi analisado o X Encuentro Nacional de Educación y Pensamiento. Globalización, Pensamiento Crítico y Pedagogía de la Liberación. Homenaje Póstumo a Paulo Freire, realizado em 2000, em Porto Rico.

A opção pelos eventos brasileiros deve-se ao fato de abordarem questões relacionadas à Educação e à abordagem freireana e vygotskyana. Pressupõe-se que, em algum momento, os estudos publicados nesses eventos refletem acerca de interlocuções entre os pressupostos de Freire e Vygotsky. A seleção do evento realizado em Porto Rico justifica-se por centralizar suas discussões em aspectos relacionados à abordagem histórico-cultural e, em especial, na décima edição, por fazer referência a Paulo Freire.

A identificação dos estudos deu-se por meio da presença de alguns elementos relacionados a Freire e Vygotsky no título e nas palavras-chave. Após a seleção dos estudos, entrou-se em contato com seus autores, que dispobililizaram outros trabalhos publicados em periódicos, livros, teses e dissertações.

Os estudos selecionados foram lidos na íntegra e analisados por meio da Análise Textual Discursiva (Moraes; Galiazzi, 2007; Moraes, 2003) que tem sido utilizada, em especial no ensino de Ciências, como um encaminhamento metodológico para a análise de pesquisas (Lindemann et al., 2009; Cirino; Souza, 2008; Gonçalves; Marques, 2006; Galiazzi, 2003). A Análise Textual Discursiva é estruturada nas seguintes etapas: unitarização — ocorre por meio da fragmentação dos textos elaborados por meio das compreensões dos trabalhos, fazendo emergir, assim, unidades de significado; categorias temáticas — as 
unidades de significado são agrupadas segundo suas semelhanças semânticas; comunicação - elaboraram-se textos descritivos e interpretativos (metatextos) acerca das categorias temáticas.

\section{Elementos articuladores}

Os trabalhos publicados em periódicos, livros, teses e dissertações, obtidos por meio dos seus autores, juntamente com as atas dos eventos, representam um total de 19 estudos que articulam o pensamento de Freire e Vygotsky. Desses, identificaram-se: 8 trabalhos publicados em Atas de eventos; 4 artigos publicados em periódicos, 1 dissertação de mestrado, 2 teses de doutorado, 1 livro e 3 capítulos de livros.

Na leitura dos 19 estudos que abordam o pensamento de Freire e Vygotsky, constatou-se que algumas pesquisas centralizam suas investigações no campo teórico da interlocução entre Freire e Vygotsky, ocasião em que explicitam convergências e divergências entre as ideias desses autores. Diversas são as interlocuções abordadas, tais como: linguagem, concepção de conhecimento e a mediação. Neste estudo, será dada particular atenção aos seguintes trabalhos: Alves (2008), Marques e Marques (2006), Moura (2001, 2004) e RodríguezArocho (2000), considerando que, no conjunto, possibilitaram uma interlocução na busca das questôes formuladas na Introdução.

\section{Linguagem}

A maioria dos estudos que articulam Freire e Vygotsky também dá atenção à linguagem verbal, sendo a palavra o foco de suas premissas. Apesar de ambos os autores recorrerem a ela em causas e preocupações distintas, Vygotsky (2005) preocupou-se com as questôes psicológicas da linguagem, realizando uma análise do processo de desenvolvimento da relação entre palavra e pensamento, enquanto Freire interessou-se originalmente pela linguagem, tendo em vista a alfabetização de jovens e adultos.

Para Marques e Marques (2006), a proposição da educação como um ato dialógico, por Freire, e da linguagem como principal elemento mediador no processo de constituição do sujeito, por Vygotsky, apresenta como ponto de convergência o diálogo na prática pedagógica. Nessa interlocução, os autores entendem que Freire defende a educação como ato dialógico, destacando a necessidade de uma razão dialógica comunicativa, em que o ato de conhecer e $\mathrm{o}$ ato de pensar estariam diretamente inter-relacionados. Em suma, segundo Marques e Marques (2006), o diálogo, em Freire, é uma relação horizontal entre pessoas, por isso tem a potencialidade de libertar oprimidos e opressores. 
Por outro lado, os autores compreendem que, para Vygotsky, são estreitas as relaçôes que ligam o pensamento humano à linguagem, uma vez que os significados das palavras, que são construídos socialmente, cumprem tanto a ação de representação quanto a de generalização, o que permite a reconstrução do real ao nível do simbólico. Essa reconstrução, no entender dos autores,

representa a condição de criação de um universo cultural e a construção de sistemas lógicos de pensamento, que possibilitam a elaboração de sistemas explicativos da realidade. Do mesmo modo, essa dupla função permite a comunicação da experiência individual e coletiva (Marques; Marques, 2006, p. 6).

Essa posição remete à discussão da palavra que, em Freire e Vygotsky, na interpretação de Alves (2008), é o encontro do ser humano com o mundo:

[...] enfatiza Freire que dizer a palavra seja transformar o mundo e, emendaria Vigotski, em sendo a palavra, a linguagem, um instrumento psicológico organizador do pensamento, já aí reside seu potencial de mudança. Talvez, então, com base no pressuposto marxista de que a validade do pensamento não é uma questão teórica, mas prática, de tudo se possa afirmar que o diálogo entre a psicologia histórico-cultural e a pedagogia freireana, se traduza efetivamente na crença de que o valor da ação educativa comprometida com o desenvolvimento humano está em compreender que é preciso, pela sua mediação, ler e apreender a realidade para transformá-la (p.187).

De forma análoga, Moura (2001) aponta que a linguagem assume um papel específico na abordagem vygotskyana e freireana:

[...] \{Vygotsky\} considera a palavra como o signo por excelência, responsável pelo desenvolvimento cultural dos sujeitos. A palavra é o signo cultural de mediação fundamental, responsável pela transformação das funções naturais de inteligência do sujeito para as funçōes superiores, ou culturais. Para Freire a palavra, como núcleo fundamental do diálogo entre os homens, implica duas dimensōes: ação e reflexão, o que as unifica na práxis. A palavra, para ele, é a mediadora do homem com o mundo. Vai mais além ao afirmar que a palavra verdadeira tem a função de transformar o mundo (Moura, 2001, p. 25).

Moura (2001) compreende que a palavra em Freire é a mediadora do homem com o mundo, com a função de transformar o mundo. Já para Vygotsky a palavra está associada à construção de sistemas lógicos de pensamento, em que, como signo, é responsável pela gênese e pelo desenvolvimento das funções psi- 
cológicas superiores. Vale salientar que os signos, além de meios na comunicação, constituem as próprias funções psicológicas superiores. Portanto, o signo é mais que "contribuição" para o seu desenvolvimento: é, primeiramente, meio de comunicação; depois, constitutivo de novas funções psicológicas superiores.

Nesse contexto, é importante destacar que a palavra é, de fato, constitutiva das funçôes psicológicas superiores em que as funções naturais continuam a operar, agora "compreendidas" por novas funções. No entender de Pino (2005), enquanto as funções biológicas se inscrevem nas estruturas genéticas da espécie, as funções psicológicas superiores passam por outra via: a da história social dos homens. Dessa forma, não há uma transformação das funções naturais em culturais, pois elas seguem caminhos diferenciados.

Moura (2001) também explicita que Freire e Vygotsky trazem, para suas reflexões e produçóes, a linguagem escrita como um instrumento fundamental de comunicação e desenvolvimento da memória. Nesse sentido, a mesma autora (2004) aponta que os autores atribuem importância à linguagem escrita no processo de alfabetização, veem a sua "apropriação" e "internalização" não como o ponto de chegada, no processo de alfabetização, mas como a possibilidade de caminhar na direção dos outros conhecimentos; como instrumento mediador de sujeitos cognoscentes, além de ser o mediador das relações dos sujeitos com o mundo.

Em suma, para Moura (2001, 2004), Marques e Marques (2006) e Alves (2008), a linguagem em Freire e Vygotsky é entendida como a centralidade do diálogo na ação pedagógica, em que afloram discussões em torno da palavra, a qual apresenta especificidades: em Freire, é a mediadora das relaçóes dos sujeitos com o mundo; em Vygotsky, tem um papel na comunicação, nas interaçōes e na gênese e no desenvolvimento das funções psicológicas superiores. Além dessa concepção dos estudos analisados, entendemos que em Freire a palavra é constitutiva de duas dimensões indicotomizáveis: reflexão e ação, ou seja, a práxis. "Não há palavra verdadeira que não seja práxis. Daí que dizer a palavra verdadeira transforma o mundo" (Freire, 1987, p. 77). Assim, para Freire (1987), alfabetizar é muito mais do que ler palavras e repeti-las, é dizer a sua palavra. A alfabetização deve propiciar a "leitura crítica do mundo", sendo ela o elemento de mediação entre os homens e a realidade em que vivem, com o propósito de compreendê-la e transformá-la.

Em Vygotsky, entende-se que a palavra, como signo, pode apresentar uma função importante no processo de mediação ? na relação entre sujeito e objeto do conhecimento ?, desde que apresente um significado; isso porque uma palavra sem significado é vazia, como qualquer som da natureza (Vygotsky, 2005).

Dessa forma, na perspectiva vygotskyana, a palavra assume um importante papel na construção de sistemas lógicos de pensamento: 
É precisamente com ela (palavra) que a criança orienta arbitrariamente a sua atenção para determinados atributos, com a palavra ela os sintetiza, simboliza o conceito abstrato e opera com ele como lei suprema entre todas aquelas criadas pelo pensamento humano (Vygotsky, 2005, p. 226).

Embora a maioria das pesquisas aponte especificidades em Freire e Vygotsky quanto ao papel da palavra, entende-se, assim como Rodríguez-Arocho (2000), que ambos os autores se complementam. A autora chama a atenção para a palavra como elemento de convergência entre Freire e Vygotsky, uma vez que ambos reconhecem que a consciência se conforma e se transforma por meio da palavra, que é constituída de uma pluralidade de significados que se constroem em contextos da atividade comunicativa. Rodríguez-Arocho (2000) reforça que Freire e Vygotsky se aproximam por reconhecerem que as palavras são signos, e, como tais, podem ser utilizadas para transformar o pensamento. Ou seja, são as palavras que influenciam diretamente no desenvolvimento cognitivo dos sujeitos e, por sua vez, na constituição da consciência.

\section{Concepção de conhecimento}

Para Marques e Marques (2006), na abordagem histórico-cultural, o meio constitui-se em fonte de conhecimento. Vygotsky empenhou-se na busca do entendimento sobre os mecanismos pelos quais a cultura se torna parte integrante da natureza de cada ser humano. Para os autores, tomando como referência o ambiente cultural, gênese e desenvolvimento do homem, a abordagem vygotskyana entende que o processo de construção do conhecimento ocorre através da interação do sujeito historicamente situado com o ambiente sociocultural onde vive. A educação precisa, nessa perspectiva, tomar como referência toda a experiência de vida própria dos indivíduos (Marques; Marques, 2006).

No entender dos autores, para Vygotsky, a construção do conhecimento procede de uma ação partilhada, que implica um processo de mediação entre sujeitos. Assim, a interação social é condição indispensável para a cultura. Segundo Marques e Marques (2006), a heterogeneidade do grupo enriquece o diálogo, a cooperação e a informação, ampliando, consequentemente, as capacidades individuais. As relações sociais constituem as funçōes mentais superiores. Quanto à construção do conhecimento, Marques e Marques (2006) entendem que

[...] a concepção da construção do conhecimento de Freire e Vygotsky tem o mesmo ponto de partida e de chegada. Freire aponta como ponto de partida as necessidades populares e 
Vygotsky, os conhecimentos espontâneos; os dois apontam o conhecimento científico como ponto de chegada (p. 8).

Os autores fundamentam essa posição, explicando que Freire aponta o conhecimento como produto das relações entre os seres humanos e destes com o mundo. Os seres humanos necessitam buscar respostas para os desafios encontrados nessas relações. Para isso, devem reconhecer a questão, compreendê-la e articular formas de respondê-la adequadamente. Daí, outras questôes se colocam e novos desafios aparecem. Assim constitui-se o conhecimento, ou seja, a partir das necessidades humanas (Marques; Marques, 2006).

No âmbito da perspectiva vygotskyana, Marques e Marques (2006) apontam que a relação entre aprendizagem e desenvolvimento remete ao entendimento da relação entre os conceitos científicos e os conceitos espontâneos da criança. Os autores afirmam que em Vygotsky o aprendizado se dá tanto na direção ascendente quanto na descendente. $\mathrm{Na}$ ascendência, o vetor indica a ação dos conceitos espontâneos, abrindo caminho para os conceitos científicos, enquanto, na descendência, indica a influência dos conceitos científicos sobre o conhecimento cotidiano, fornecendo as estruturas para o desenvolvimento ascendente deste, sempre numa relação dialética. Assim, o conhecimento, tanto o científico quanto o cotidiano, é produção cultural.

Com base nisso, para Marques e Marques (2006), a gênese do conhecimento - científico ou cotidiano - , em Freire, está nas necessidades humanas; e, em Vygotsky, na produção cultural. Além dessa compreensão de Marques e Marques (2006), é importante lembrar que a cultura humana em Vygotsky (2001) também parte das necessidades, em que é o meio cultural que cria, move e mobiliza a ação do homem. Isto é, o meio cultural é a gênese da necessidade de sobrevivência nesse meio em que as pessoas buscam a sua identidade. Por exemplo, em determinados grupos de jovens, alguns aspectos como a roupa e a opção musical, os conhecimentos e os ideais que defendem, são fatores determinantes para que possam fazer parte do grupo. Ou seja, a apropriação de aspectos relacionados ao meio cultural em que vivem os jovens é condição para a sua participação.

Outro aspecto que consideramos pertinente na obra de Vygotsky (2001) diz respeito à tomada de consciência de conhecimentos espontâneos através do conhecimento de maior generalidade (científico) que o autor referencia. Para ele, esses conhecimentos são o ponto de partida; e a tomada de consciência, o ponto de chegada.

A partir da compreensão de Marques e Marques (2006) acerca da relação entre conhecimento científico e espontâneo, entendemos que alguns aspectos necessitam ser questionados, por exemplo: em que sentido, para Vygotsky, 
conceitos espontâneos relacionam-se com a produção cultural e com os conceitos científicos? E, ainda, qual a origem dos conceitos espontâneos em Vygotsky? Talvez essas indagações possam ser esclarecidas a partir da compreensão da gênese da consciência real efetiva ${ }^{1}$ em Freire (1987) e dos conhecimentos espontâneos em Vygotsky, discussão que necessita de aprofundamentos.

Compreensão análoga à de Marques e Marques (2006) é expressa por Alves (2008):

[...] encontram-se Vigotski e Freire para, respeitadas as especificidades da pedagogia e da psicologia, explicitar suas concepções acerca do papel da escola no processo de construção do conhecimento, que é, por sua vez, fonte de desenvolvimento humano. Para ambos, a gênese do conhecimento encontra-se na práxis, ou seja, na prática social dos homens historicamente situados. (p. 171- grifo nosso).

A autora, ao apontar que a gênese do conhecimento em Freire e Vygotsky se encontra na vivência, no mundo em que vivem os sujeitos que são históricos, amplia as discussões e sinaliza que ambos os autores também se aproximam, no que diz respeito ao princípio teórico e epistemológico sobre o conhecimento. Com isso, Alves (2008) passa a configurar a concepção de conhecimento em cada autor: em Freire, é um ato de conscientização, pela qual o ser humano realiza o movimento de tomar para si a realidade na qual se insere; em Vygotsky, no contexto do desenvolvimento psicológico, o conhecimento está relacionado ao processo de elaboração conceitual, em que o conceito é construção social. Para a autora, esse processo, em Freire e Vygotsky, está vinculado ao ato de distanciamento do objeto, de modo a apropriar-se dele, seja como processo de abstração e generalização (Vygostky) ou como movimento de "ad-miração" do real, vendo-se nele (Freire).

Alves (2008) também menciona que a "gênese do conhecimento encontrase na práxis", porém não explora a relação dos distintos conhecimentos, para Freire e Vygotsky, com a práxis. Com base nesse entendimento da autora, chamamos a atenção para o fato de que a práxis pode apresentar distintas origens, ou seja, pode estar atrelada a distintos conhecimentos/conceitos. Isto é, a práxis pode encontrar-se vinculada aos conhecimentos espontâneos, assim como também aos conhecimentos mais elaborados. Por exemplo, em Freire (1987), a práxis ? ação e reflexão dos homens sobre o mundo ? está relacionada com as contradições existenciais, determinando, assim, a necessidade de conhecimen-

I. Freire (1987, p. 138), tendo como referência Goldman, identifica a consciência real efetiva como aquela pela qual "os homens se encontram limitados nas suas possibilidades de perceberem além das situações-limites". 
tos científicos para a sua compreensão. Em Vygotsky, esse aspecto está relacionado com a necessidade de maior generalidade (própria do conhecimento científico), isso porque, num mundo complexo, a "necessidade" de sobrevivência cultural está dada, é uma construção histórica.

Moura (2004) entende que há divergências entre Freire e Vygotsky quanto à concepção de conhecimento e afirma que:

Para Vygotsky esses conhecimentos [científicos] são as referências para a elevação dos conhecimentos espontâneos, portanto, deve-se partir não do conhecimento espontâneo ou do desenvolvimento real do aluno, mas daqueles conhecimentos que ainda não possui, mas que estão na área de desenvolvimento proximal [...] Freire distancia-se completamente [...] ele vê nos conhecimentos do cotidiano o ponto de partida para aquisição e formação dos conhecimentos científicos, no processo de alfabetização deve-se partir dos conhecimentos da realidade dos alfabetizadores (p. 183, grifo nosso).

A autora revela que o ponto de partida no processo educacional em Vygotsky está relacionado com os conceitos científicos. Todavia, ressaltamos que na obra vygotskyana -embora tenha como referência fundamental os conceitos científicos - não há informações quanto à necessidade de partir desses conceitos para a organização didático-pedagógica na sala de aula, já que o autor também considera o papel dos conceitos espontâneos no processo de desenvolvimento cognitivo.

Para Vygotsky (1982), que defende a existência de vínculos e movimentos em sentidos opostos entre os conhecimentos, no processo de formação dos conceitos científicos e cotidianos há uma influência mútua entre eles, o que permite a evolução de ambos.

[...] o conceito espontâneo da criança desenvolve-se de baixo para cima, das propriedades mais elementares e inferiores às superiores, ao passo que os conceitos científicos se desenvolvem de cima para baixo, das propriedades mais complexas e superiores para as mais elementares e inferiores (Vygotsky, 1982, p. 252 , tradução nossa).

Nesse caminho diferenciado dos dois tipos de conceitos, a aprendizagem científica não se configura como uma mudança conceitual, mas como a "passagem de uma forma de conceituar para outra" (Pozo et al., 1991). Esse fato possibilita que os conhecimentos alcancem novos níveis de desenvolvimento, ou seja, evoluam em significado, passando a níveis mais abstratos. Assim, não há transformação de um sistema de conceitos em outro, como também o pon- 
to de partida não está centralizado no conhecimento científico, pois há uma influência recíproca que permite a evolução de ambos em suas vias próprias e diferenciadas. Aspecto que se dá num processo dialético, o que significa que a vivência e a intencionalidade da significação (pedagógica) dos conhecimentos estão presentes desde o início.

Além disso, Moura (2004), ao apontar que os conceitos científicos são ponto de partida no processo educacional, não explicita os sujeitos aos quais está se referindo. Em outros termos, os conceitos científicos são ponto de partida para o professor/programador/planejador? Para Vygotsky, qual o ponto de partida das situaçôes de sala de aula? Nesse sentido, é de suma importância dar maior atenção ao processo de formação de conceitos em Vygotsky, para que se possa compreender a qual situação ele está se referindo. Em outras palavras, é necessário esclarecer, na perspectiva vygotskyana, a relação entre a organização didático-pedagógica e os conhecimentos científicos e espontâneos.

Moura (2004), porém, enfatiza que, em Freire, os conhecimentos da vivência dos sujeitos assumem o ponto de partida no processo educacional. É importante ressaltar que a autora não explicita a importância que os conhecimentos científicos assumem na proposta freireana, ou seja, não menciona a Redução Temática (Freire, 1987) ? processo que culmina com a seleção de conhecimentos compartilhados por especialistas para a compreensão dos Temas Geradores (Freire, 1987), conforme aponta Delizoicov (1991, 2008). Chama-se a atenção para o fato de que alguns autores, ao fazerem referência a Freire, em especial aos Temas Geradores, sinalizam que estes estão relacionados com a vivência dos educandos, mas, equivocadamente, não mencionam o papel dos conhecimentos historicamente produzidos, inseridos na Redução Temática por especialistas, segundo proposição de Freire (1987). Tal omissão tem gerado a acusação de que as ações pedagógicas, baseadas na concepção freireana, são "espontaneístas" e "reducionistas" (Delizoicov, 1991). De fato, no contexto de sala de aula, a Redução Temática ? quarta etapa da Investigação Temática² (Freire, 1987) ? inclui os conhecimentos científicos, os quais são ponto de chegada no processo de ensino-aprendizagem, pois contribuem para o entendimento dos Temas Geradores (Delizoicov, 1991, 2008; Pontuschka, 1993; Silva, 2004; Delizoicov, Angotti e Pernambuco, 2002).

2. Sistematizado por Delizoicov (199|, 2008) em cinco etapas, a partir da proposição apresentada no capítulo 3 do livro Pedagogia do oprimido (Freire, 1987): primeira (levantamento preliminar): reconhecer o ambiente em que vive o aluno. Segunda (análise das situações e escolha das codificações): escolha de situações que sintetizam as contradições vividas. Terceira (diálogos descodificadores): a partir desses diálogos se obtêm os Temas Geradores. Quarta (redução temática): trabalho de uma equipe interdisciplinar, com o objetivo de elaborar o programa e identificar quais conhecimentos disciplinares são necessários para o entendimento dos temas. Quinta (trabalho em sala de aula): desenvolvimento do programa em sala de aula.

Pro-Posições, Campinas, v. 21, n. 1 (61), p. 129-148, jan./abr. 2010 
Ressalta-se que a referência de conceitos científicos para constituir programas escolares não é a mesma que se aplica a esses conceitos como ponto de partida, pois, para o professor, que estrutura os conteúdos programáticos, o conhecimento científico é composto por construções históricas já apropriadas por ele, mas não ainda pelo próprio aluno. Para que o aluno se aproprie desse conhecimento, no contexto de sala de aula, Freire (1987) propõe que o diálogo se inicie em torno da problematização de questôes que estejam próximas de sua realidade, de contradiçóes existenciais e sociais.

Em síntese, os trabalhos apresentam convergências e divergências quanto ao processo de construção de conhecimento apresentado por Freire e Vygotsky, em que afloram questôes vinculadas ao processo educacional, em especial ao seu ponto de partida. $\mathrm{Na}$ visão das pesquisas, o ponto de partida em Vygotsky é compreendido como a palavra significada, o conceito abstrato; e em Freire representa as situações da vivência, o contexto em que o educando está imerso. Conforme mencionado anteriormente, Vygotsky não explicita em sua obra que o ponto de partida do processo educacional está centrado nos conceitos científicos. Em seus estudos, mostra que o conhecimento escolar, que tem como referência conhecimentos de maior generalidade, permite a tomada de consciência de situaçôes da vivência; portanto, dos conhecimentos prévios. Vygostky (2001) tem em vista, como conhecimento de maior generalidade, um sistema conceitual ou o conhecimento científico. Isso é diferente de apenas considerar a palavra como conceito; é considerar as palavras dentro de um sistema sub e superordenado.

Também é importante destacar que os estudos analisados não dão a devida atenção ao ponto de partida em Freire (1987) que, embora esteja relacionado com as contradições existenciais dos educandos, é sintetizado na Palavra Geradora e/ou Tema Gerador que se constituem em códigos, isto é, signos com caráter polissêmico, que podem ser associados aos conhecimentos espontâneos e científicos.

\section{Mediação}

Elementos relacionados à mediação também são explorados pelas pesquisas que articulam o pensamento de Freire e Vygotsky. Para Moura (2004), ambos os autores, ao defenderem uma educação comprometida pedagógica e politicamente com a socialização/apropriação da cultura por todos os sujeitos, trazem para a discussão elementos relacionados ao processo da mediação.

[...] os "instrumentos psicológicos" de Vygotsky correspondem às "codificaçōes" e "descodificaçōes" de Freire. As "codificaçōes" são concebidas como representação de uma dada realidade, que 
media o processo de análise do sujeito e a sua conseqüente conscientização no sentido de analisar esta realidade e buscar novos instrumentos de intervenção, enquanto que a mediação principal se faz através da palavra, constituída num sistema de signos, o diálogo (p.187).

Na compreensão de Moura (2004), são os signos que assumem a função de mediadores no processo da apropriação de conhecimentos, em que o professor, responsável pela finalidade das atividades realizadas no contexto escolar, deve controlar os sentidos para que os significados possam ser construídos com a devida assimetria; isto é, para que estes estejam dentro da Zona de Desenvolvimento Proximal (ZDP). O professor, caracterizado como "mediador", dirige os significados produzidos nas interações sociais, em que há sempre uma intenção, uma finalidade nas atividades realizadas. $\mathrm{Na}$ visão da autora, em Freire são as situações de codificação ${ }^{3}$ e a descodificação que assumem a função de mediadores na relação entre sujeito e objeto do conhecimento, e o professor tem o papel de organizar as discussões em torno delas, como aponta Moura (2004):

Freire defende essa posição porque para ele a mediação entre aluno e objeto a ser aprendido se dá pelas situações de "codificação" e "descodificação", em que cabe ao educador o papel de oferecer estas mediações e coordenar os debates e descobertas em torno dela. Assim, a postura do alfabetizador é dialogar com os alfabetizadores sobre essas informações (p. 188).

Destaca-se que a mediação pode estar relacionada à interação entre sujeito e objeto do conhecimento, numa dimensão epistemológica, como caracteriza Pino (1995), sendo o signo o agente mediador, assim como nas interaçôes pedagógicas o professor é o agente mediador na relação entre aluno e objeto do conhecimento, em que o signo também é importante. Então, pode-se dizer que o signo assume dupla função: o de agente mediador e de objeto do conhecimento.

Alves (2008) também apresenta aspectos relacionados à descodificação presente em Freire como elemento articulador com a perspectiva vygotskyana e aponta que:

A descodificação, afirma o autor [Freire], é um ato cognoscente. É um momento de ad-mirar, de distanciar-se do cotidiano para vê-lo a partir de outro lugar. Já aqui, portanto, acontecem processos de aprendizado e, diria Vigotski, constituem-se terrenos férteis para o desenvolvimento de funções psicológicas superio-

3. Envolvem as situações e compreensões da realidade em que se encontram imersos os sujeitos. 
res, na medida em que tal exercício demanda um processo de abstração, de construção de hipóteses sobre a realidade, de construção de análises e produção de sínteses. O que, por sua vez, implica reflexão, classificação, organização no âmbito cognitivo (2008, p. 168).

A autora parece atribuir ao processo da descodificação presente em Freire uma possível complementaridade com Vygotsky, ao apontar que esse processo se constitui num espaço propício para o desenvolvimento das funções mentais superiores, pois demanda abstração. Embora essa articulação seja plausível, ressalta-se que a descodificação está associada ao processo de codificaçãoproblematização-descodificação (Freire, 1987). Assim, parece que, durante todo esse processo, que é dinâmico, possa haver desenvolvimento cognitivo, pois é a problematização que possibilita a abstração de códigos (situações vivenciais, ainda não problematizadas), bem como a descodificação.

Já Rodríguez-Arocho (2000) sinaliza que tanto o Tema Gerador (Freire) quanto os signos (Vygotsky) são entendidos como mediadores. Ou seja, ambos assumem o elo mediador entre o sujeito e o objeto do conhecimento no processo de ensino-aprendizagem:

La necesidad de situar sociohistóricamente el discurso también fue trabajada por Freire en la noción de "unidad epocal", por la que se refirió a la especificidad y particularidades de los contextos históricoculturales. Para Freire, una unidad epocal se caracteriza por sus "temas generadores". La conceptualización freiriana de los temas generadores captura la idea del poder condensación que Vygotski atribuyó al signo (p.125). [...] La noción de temas generadores captura la idea vygotskiana del signo, que implica la condensación de actividades, a la vez que crea la posibilidad de otras actividades (Rodríguez-Arocho, 2000, p. 7).

Com base nessa possível relação entre Tema Gerador e signos, chama-se a atenção para o fato de que em Freire a palavra (geradora) é o ponto de partida do processo educacional. Contudo, ela não está vinculada exclusivamente aos conhecimentos espontâneos, mas também aos conhecimentos científicos necessários e selecionados durante o processo de Redução Temática para a compreensão do Tema Gerador. Essa semelhança entre Tema Gerador e signos reforça que a palavra, na perspectiva freireana, também pode representar os conhecimentos historicamente construídos, concepção que parece estar ausente em Moura (2004).

Além dessa possível articulação entre Freire e Vygotsky, Rodríguez-Arocho (2000) também apresenta indicativos quanto à concepção educacional de Freire estar em sintonia e/ou complementar-se com a ZDP, proposta por Vygotsky. 
Freire aboga por una educación problematizadora y liberadora, como Vygotski abogó por un aprendizaje que incidiera en la zona de desarrollo próximo, que facilitara y guiara el movimiento del nivel actual de entendimiento a un nivel de mayor complejidad cognoscitiva (Rodríguez-Arocho, 2000, p. 8).

Ao trazer elementos do Tema Gerador, Rodríguez-Arocho (2000) considera muito mais que a possível articulação entre a codificação, a descodificação (Freire) e os instrumentos psicológicos (Vygotsky), indo além dessa proposição apresentada por Alves (2008) e Moura (2004).

Embora Rodríguez-Arocho (2000) destaque a relação que Freire (1987) estabelece entre Tema Gerador e uma unidade epocal ? que situa especificidades e particularidades de contextos históricos culturais e na perspectiva de uma educação problematizadora ?, nesse sentido não faz referência explícita à problematização e nem à Investigação Temática. Além disso, a autora deixa margens para interpretações que estão próximas de uma possível sintonia entre o processo de codificação-problematização-descodificação e a atuação educativa na ZDP proposta por Vygotsky, que pode estar relacionada aos níveis de "consciência real efetiva e consciência máxima possível”", abordados por Freire (1987). Contudo, Rodríguez-Arocho (2000) não explora essa possibilidade de forma sistemática, aspecto que carece de investigaçōes.

Em suma, os estudos de Moura (2004) e Alves (2008) explicitam uma possível articulação entre a perspectiva vygotskyana e a freireana, por meio do processo de codificação e descodificação, assim como Rodríguez-Arocho (2000) aponta a relação dos Temas Geradores com os signos e da concepção educacional de Freire com a ZDP. Todavia, não há referência explícita nesses estudos quanto à possibilidade de a problematização ? fundamental no processo de codificação-problematização-descodificação ? também ser um possível elemento articulador entre a teoria de Freire e Vygotsky, no sentido de abordar determinados problemas que são manifestações locais de contradições (Freire, 1987) presentes na vivência dos sujeitos.

\section{Considerações e contribuições para a Educação em Ciências}

As discussões em torno das ideias de Freire e Vygotsky exploradas pelas pesquisas apontam como elementos de interlocução a linguagem, a concepção de conhecimento e a mediação. Além disso, destaca-se a ênfase dada pelas

4. Para Freire (1987), a consciência máxima possível é denominada como "soluções praticáveis despercebidas", categoria análoga à consciência crítica, utilizada pelo autor em produções anteriores.

Pro-Posições, Campinas, v. 21, n. 1 (61), p. 129-148, jan./abr. 2010 
pesquisas ao processo de codificação, à descodificação e ao Tema Gerador ? presentes na perspectiva freireana ?, que podem ser associados, respectivamente, aos signos, em Vygotsky. Embora não haja uma referência ao problema, à problematização ? tal qual concebido por Freire ?, o fato de os estudos sinalizarem tais interlocuções indica que há uma compreensão implícita do caráter problematizador também na perspectiva vygotskyana.

A ausência, nos estudos, da problematização no contexto da perspectiva freireana pode estar vinculada à pouca ênfase dada à sua dimensão epistemológica. Para Freire (1987), a problematização consiste em abordar determinados problemas que são manifestaçôes locais de contradições (Freire, 1987) e fazem parte da vivência dos educandos; é exercer uma análise crítica sobre a "realidade problema", para que o educando perceba essa questão e reconheça a necessidade de mudanças. Nas palavras de Freire (1987), seriam, nesse momento, exploradas aquelas situaçóes que se colocam como fronteira para a compreensão da realidade vivida pelos sujeitos, ou seja, as "situações-limites". Isso porque é na problematização que começa a formação da nova percepção e do novo conhecimento ligado à "consciência máxima possível”.

No contexto da Educação em Ciências, Delizoicov (1991, 2002) discute a problematização, articulando as ideias de Freire e Bachelard no que diz respeito à aquisição de conhecimento científico. Aponta que ambos enfatizam a "matriz problematizadora" do conhecimento e a problematização do conhecimento a ser apreendido pelo estudante, conforme aponta Freire (2002):

[...] nenhum pensador, como nenhum cientista, elaborou seu pensamento ou sistematizou seu saber científico sem ter sido problematizado, desafiado. Embora isso não signifique que todo homem desafiado se torne filósofo ou cientista, significa, sim, que o desafio é fundamental à constituição do saber [...] se o conhecimento científico e a elaboração do pensamento rigoroso não podem prescindir de sua matriz problematizadora, a apreensão deste conhecimento científico e do rigor deste pensamento filosófico não pode prescindir igualmente da problematização que deve ser feita em torno do próprio saber que o educando deve incorporar (Freire, 2002, p. 54).

Assim, é de suma importância ampliar aspectos relativos ao problema/ problematização em Vygotsky, pois partimos do pressuposto de que o autor

5. Baseado nas ideias do prof. Álvaro Vieira Pinto, Freire (1987) entende que as situações-limites são situações que desafiam de tal forma a prática dos homens que é necessário enfrentá-las e superá-las para prosseguir. Elas "não devem ser tomadas como se fossem barreiras insuperáveis, mas além das quais nada existe" (Freire, 1987, p. 90). 
também dá ênfase ao problema e, com isso, é importante aprofundar essa dimensão de modo a identificar outras possíveis sintonias com Freire.

No que tange à Educação em Ciências, é importante destacar que, neste estudo, os trabalhos identificados nos Encontros Nacionais de Pesquisa em Educação em Ciências (Enpec) e também por Gehlen, Schoeder e Delizoicov (2007) ? que, de alguma forma, procuram fazer uma relação entre Freire e Vygotsky ?, ficam no contexto da resolução de problemas. Isto é, o foco em questão são problemas e exercícios de lápis e papel que compreendem, basicamente, indicação e orientação fornecida pelo educador para que o aluno se aproprie do conhecimento historicamente construído sem, contudo, estabelecer relações com a perspectiva da problematização em Freire.

Outro aspecto a destacar nas pesquisas é a pouca ênfase dada à significação conceitual, fundamental na perspectiva vygotskyana. Nesse sentido, é importante trazer à tona o papel da palavra, sobre o qual, muito embora Vygotsky não tenha desenvolvido uma proposta pedagógica, estudos no contexto do ensino de Ciências têm apontado para a organização curricular com base em Situações de Estudo (Maldaner, 2007). Nessa organização curricular, a compreensão necessária da situação é buscada com a introdução de palavras/conceitos que vão permitir a formação de um pensamento de maior generalidade. Ao situar o conceito no contexto da vivência do aluno, através do uso induzido da palavra que o representa desde o início, sucessivas Situações de Estudo permitem sua retomada em diversos níveis e contextos, fazendo com que evolua em seu significado.

Apesar de os estudos explorarem aspectos relacionados à interlocução entre Freire e Vygotsky, há necessidade de compreender melhor a aproximação/ complementaridade na dimensão pedagógica, aspecto pouco explorado nos estudos analisados. Com isso, amplia-se a discussão da problematização (Freire) e da significação conceitual (Vygotsky) no contexto de práticas educativas, de modo a sinalizar contribuições para a educação em Ciências, em especial, na reestruturação curricular.

\section{Referências bibliográficas}

ALVES, S. M. P. Freire e Vigotski: o diálogo entre a pedagogia freireana e a psicologia históricocultural. Tese (Doutorado) — Faculdade de Educação, Universidade de São Paulo, São Paulo, 2008.

CIRINO, M. M.; SOUZA, A. R. O discurso de alunos do ensino médio a respeito da "camada de ozônio". Ciência \& Educação, Bauru/SP, v. 14, n. 1, p. 115-134, 2008.

DELIZOICOV, D. Conhecimento, tensôes e transiçôes. Tese (Doutorado) - Faculdade de Educação, Universidade de São Paulo, São Paulo, 1991. 
DELIZOICOV, D. Problemas e problematizações. In: PIETROCOLA, M. (Org.) Ensino de Física: conteúdo, metodologia e epistemologia em uma concepção integradora. Florianópolis: Editora da UFSC, 2002. p. 125- 150.

DELIZOICOV, D. La educación en Ciencias y la perspectiva de Paulo Freire. Alexandria. Revista de Educação em Ciência e Tecnologia. v. 1, n. 2, p. 37-62, 2008. Disponível em: <http:/ /www.ppgect.ufsc.br/alexandriarevista/numero_2/artigos/demetrio.pdf >. Acesso em: 20 de janeiro de 2009.

DELIZOICOV, D.; ANGOTTI, J. A.; PERNAMBUCO, M. M. Ensino de Ciências: fundamentos e métodos. São Paulo: Cortez, 2002.

FREIRE, P. Pedagogia do oprimido. 17. ed. Rio de Janeiro: Paz e Terra, 1987.

FREIRE, P. Extensão ou comunicação? Rio de Janeiro: Paz e Terra, 2002.

GALIAZZI, M. C. Educar pela pesquisa: ambiente de formação de professores de Ciências. Ijuí: Unijuí, 2003.

GEHLEN, S. T.; AUTH, M. A.; AULER, D.; ARAÚJO, M. C. P; MALDANER, O. A. Freire e Vigotski no contexto da educação em Ciências: aproximaçōes e distanciamentos. Ensaio Pesquisa em Educação em Ciências, Belo Horizonte/MG, v. 10, n. 2, 2008.

GEHLEN, S. T.; SCHROEDER, E.; DELIZOICOV, D. A abordagem histórico-cultural no Encontro Nacional de Pesquisa em Educação em Ciências. In: ENCONTRO NACIONAL DE PESQUISA EM EDUCAÇÃO EM CIẾNCIAS (ENPEC), 6., 2007, Florianópolis. Atas...

GONÇALVES, F. P.; MARQUES, C. A. Contribuições pedagógicas e epistemológicas em textos de experimentação no ensino de química. Investigaçôes em Ensino de Ciências, v. 11, n. 2, 2006. Disponível em: <http://www.if.ufrgs.br/ienci/artigos/Artigo_ID151/ v11_n2_a2006.pdf>. Acesso em: 13 mar. 2009.

LINDEMANN, R. H.; MUENCHEN, C.; GONÇALVES, F. P; GEHLEN, S. T. Biocombustívies e o ensino de Ciências: compreensões de professores que fazem pesquisa na escola. Revista Electrónica de Enseñanza de las Ciencias (REEC), v. 8 n. 2, 2009. Disponível em: <http://www.saum.uvigo.es/reec/Volumenes.htm>. Acesso em: 02 mar. 2009.

MALDANER, O. A. Situações de estudo no Ensino Médio: nova compreensão de educação básica. In: NARDI, R. (Org.). Pesquisa em ensino de Ciências no Brasil: alguns recortes. Escrituras: São Paulo, p. 237-253, 2007.

MALDANER, O. A.; ZANON, L. B. Situação de estudo: uma organização do ensino que extrapola a formação disciplinar em Ciências. Espaços da Escola. Ijuí: Unijuí, ano 11, n. 41, p. 45-60, 2001.

MARQUES, L. P.; MARQUES, C. A. Dialogando com Paulo Freire e Vygotsky sobre Educação. In: REUNIĀO ANUAL DA ASSOCIAÇĀO NACIONAL DE PÓS-GRADUAÇĀO E PESQUISA EM EDUCAÇĀO (ANPED), 29., 2006, Caxambu/MG.

MONTEIRO, I. C. C.; GASPAR, A. Um estudo sobre as emoções no contexto das interações em sala de aula. Investigações em Ensino de Ciências. v. 12, n. 1, p. 71-84, 2007. Disponível em: <http:/ /www.if.ufrgs.br/ienci/artigos/Artigo_ID162/v12_n1_a2007.pdf>. Acesso em: 10 fev. 2009. 
MONTEIRO, M. A. A.; MONTEIRO, I. C. C.; VILLANI, A.; GASPAR, A. Motivação e interação social: o discurso do professor em uma atividade de demonstração. In: ENCONTRO NACIONAL DE PESQUISA EM EDUCAÇÃO EM CIÊNCIAS (ENPEC), 6., 2007, Florianópolis. Atas....

MORAES, R. Uma tempestade de luz: a compreensão possibilitada pela análise textual discursiva. Ciência \& Educação, Bauru/SP, v. 9, n. 2, p. 191-211, 2003.

MORAES, R.; GALIAZZI, M. C. Análise textual discursiva. Ijuí: Unijuí, 2007.

MORTIMER, E. F. Linguagem e formação de conceitos no ensino de Ciências. Belo Horizonte: Ed. UFMG, 2000.

MORTIMER, E. F.; SCOTT, P. Atividade discursiva nas aulas de Ciências: uma ferramenta sociocultural para analisar e planejar o ensino. Investigaçôes em Ensino de Ciências, v. 7, n. 3, 2002. Disponível em: <http://www.if.ufrgs.br/ienci/artigos/Artigo_ID94/ v7_n3_a2002.pdf>. Acesso em: 20 mar. 2009.

MOURA, T. M. M. Aproximações entre as idéias de Freire e Vygotsky: importância para a prática pedagógica com jovens e adultos. In: COLÓQUIO INTERNACIONAL PAULO FREIRE, 2001, Recife/PE.

MOURA, T. M. M. A prática pedagógica dos alfabetizadores de jovens e adultos: contribuições de Freire, Ferreiro e Vygotsky. 2. ed. Maceió: Edufal, 2004.

OSTERMANN, F.; CAVALCANTI, C. J. H; PRADO, S. D.; RICCI, T. S. F. Fundamentos da física quântica à luz de um interferômetro virtual de Mach-Zehnder. Revista Electrónica de Enseñanza de las Ciencias, v. 8 n. 3, 2009. Disponível em: <http://www.saum.uvigo.es/reec/ Volumenes.htm>. Acesso em: 01 out. 2009.

PEREIRA, A.; OSTERMANN, F.; CAVALCANTI, C. O ensino de Física Quântica na perspectiva sociocultural: uma análise de um debate entre futuros professores mediado por um interferômetro virtual de Mach-Zehnder. Revista Electrónica de Enseñanza de las Ciencias, v. 8 n. 2, 2009. Disponível em: <http://www.saum.uvigo.es/reec/Volumenes.htm>. Acesso em: 01 out. 2009.

PERNAMBUCO, M. M. C. A. et al. Projeto ensino de Ciências a partir de problemas da comunidade. In: SEMINÁRIO CIÊNCIA INTEGRADA E/OU INTEGRAÇÃO ENTRE AS CIÊNCIAS: TEORIA E PRÁTICA, 1988, Rio de Janeiro. Atas... Rio de Janeiro: Ed .UFRJ, 1988.

PINO, A. S. Semiótica e cognição na perspectiva histórico-cultural. Temas em Psicologia, n. 2, 1995.

PONTUSCHKA, N. N. (Org.) Ousadia no diálogo: interdisciplinaridade na escola pública. São Paulo: Cortez, 1993.

POZO, J. A.; SANZ, A.; GÓMEZ CRESPO, M. A.; LIMÓN, M. Las ideas de los alumnos sobre la Ciencia: una interpretación desde la Psicología cognitiva. Enseñanza de las Ciencias, Barcelona/Espanha v. 9, n. 1, p. 83-94, 1991.

RODRÍGUEZ-AROCHO, W. El tema de la conciencia en la psicología de Vygotski y en la pedagogía de Freire: implicaciones para la educación. In: ENCUENTRO NACIONAL DE 
EDUCACIÓN Y PENSAMIENTO, 10., 2000, San Juan/Puerto Rico. . Disponível em: <http://generales.uprrp.edu/pddpupr/docs/El\%20tema\%20de\%20la\%20conferencia $\%$ 20Vygotsky,\%20Freire.htm>. Acesso em: 20 dez. 2008.

SILVA, A. F. G. A construção do currículo na perspectiva popular crítica: das falas significativas às práticas contextualizadas. Tese (Doutorado) — Pontifícia Universidade Católica de São Paulo, São Paulo, 2004.

TORRES, J. R.; GEHLEN, S. T.; MUENCHEN, C.; GONÇALVES, F. P; GONÇALVES, F. J. F.; LINDEMANN, R. H. Ressignificação curricular: contribuições da investigação temática e da análise textual discursiva. Revista Brasileira de Pesquisa em Educação em Ciências, ABRAPEC: Belo Horizonte, v. 8, n. 2, p. 1-13, 2008.

VYGOTSKY, L. S. Incluye pensamento y lenguaje: conferencias sobre Psicología. Obras Escogidas II. Trad. José María Bravo. Madrid: Visor, 1982. (Coleción aprendizaje).

VYGOTSKY, L. S. A formação social da mente. 6. ed. São Paulo: Martins Fontes, 1998.

VYGOTSKY, L. S. A construção do pensamento e da linguagem. Trad. Paulo Paulo Bezerra. São Paulo: Martins Fontes, 2001.

VYGOTSKY, L. S. Pensamento e linguagem. Trad. Jefferson Luiz Camargo. 3. ed. São Paulo: Martins Fontes, 2005.

Recebido em 16 de abril de 2009 e aprovado em 18 de setembro de 2009. 